\title{
$2^{2 n-k} \times 2^{k}$ 토러스와 $\operatorname{HFN}(n, n), \operatorname{HCN}(n, n)$ 사이의 임베딩 알고리즘
}

\author{
김 종 석 ${ }^{\dagger}$ 강 민 식 ${ }^{\dagger+}$
}

\author{
요 약
}

\begin{abstract}
본 논문에서는 $2^{2 n-k} \times 2^{k}$ 토러스 연결망과 상호연결망 $\operatorname{HFN}(n, n)$ 과 $\operatorname{HCN}(n, n)$ 사이의 임베딩을 분석한다. 먼저, $2^{2 n-k} \times 2^{k}$ 토러스를 $\operatorname{HFN}(n, n)$ 에 연장율 3 과 밀집율 4 로 임베딩 가능함을 보이며, 평균연장율이 2 이하임을 증명한다. 그리고 $2^{2 n-k} \times 2^{k}$ 토러스를 $H C N(n, n)$ 에 연장율 3 으로 임 베딩 가능함을 보이며, 평균 연장율이 2 이하임을 증명한다. 또한 $\operatorname{HFN}(n, n)$ 과 $\operatorname{HCN}(n, n)$ 이 $2^{2 n-k} \times 2^{k}$ 토러스에 임베딩하는 연장율이 $O(n)$ 임을 보인다. 이러한 결과는 토러스에서 개발된 여러 가지 알고리즘을 $\operatorname{HCN}(n, n)$ 과 $\operatorname{HFN}(n, n)$ 에서 효율적으로 이용할 수 있음을 의미한다.
\end{abstract}

키워드 : 토러스, $\operatorname{HFN}(n, n), \operatorname{HCN}(n, n)$,임베딩

\section{Embedding Algorithm between $2^{2 n-k} \times 2^{k}$ Torus and $\operatorname{HFN}(n, n), \operatorname{HCN}(n, n)$}

\author{
Jong-Seok $\mathrm{Kim}^{\dagger} \cdot$ Min-Sik Kang ${ }^{\dagger+}$
}

\begin{abstract}
In this paper, we will analysis embedding between $2^{2 n-k} \times 2^{k}$ torus and interconnection networks $H F N(n, n), H C N(n, n)$. First, we will prove that $2^{2 n-k} \times 2^{k}$ torus can be embedded into $\operatorname{HFN}(n, n)$ with dilation 3, congestion 4 and the average dilation is less than 2 . And we will show that $2^{2 n-k} \times 2^{k}$ torus can be embedded into $\operatorname{HCN}(n, n)$ with dilation 3 and the average dilation is less than 2. Also, we will prove that interconnection networks $\operatorname{HFN}(n, n)$ and $\operatorname{HCN}(n, n)$ can be embedded into $2^{2 n-k} \times 2^{k}$ torus with dilation $O(n)$. These results mean so many developed algorithms in torus can be used efficiently in $H F N(n, n)$ and $H C N(n, n)$.
\end{abstract}

Key Words: Torus, $\operatorname{HFN}(n, n), \operatorname{HCN}(n, n)$, embedding

\section{1. 서 론}

컴퓨터를 이용하는 현대의 과학과 공학 분야에서는 많은 계산을 수행하면서 빠른 시간에 해를 구해야 하므로 기존의 컴퓨터보다 더욱 빠른 계산 능력을 갖는 고성능 컴퓨터에 대한 연구가 지속되고 있다. 컴퓨터의 속도를 결정하는 첫 번째 요소인 프로세서의 속도는 계속 향상되고 있지만 필요 한 정도의 시스템 성능을 얻기에는 여전히 부족하다. 최근 대부분의 컴퓨터 설계에서 성능 향상을 위한 방법으로써 병 렬 처리(parallel processing) 기술이 널리 사용되고 있다. 병 렬 처리에 있어서 상호연결망(Interconnection network)은 매우 중요한 요소이다. 상호연결망은 각 프로세서들을 노드 로, 프로세서들 사이의 통신 채널을 에지로 나타내는 무방 향 그래프로 표현된다. 대표적인 상호연결망으로 트리, 메쉬 [5], 하이퍼큐브[4,7], Hierarchical Cubic Network(HCN)

\footnotetext{
† 준 회 원:오클라호마 주립대학교 컴퓨터과학과 박사후연구원

†† 정 회 원:(주)보고정보 기획영업팀 차장

논문접수: 2007년 6월 24일, 심사완료 : 2007년 9월 22일
}

[11,17], Hierarchical Folded-hypercube Network(HFN)[6], 스타그래프[1] 등이 제안되었다.

상호연결망에서 메쉬 구조는 평면그래프로서 VLSI 회로 설계 같은 분야에서 많이 이용되는 구조로 현재까지 널리 이용되고 있으며 다양한 시스템으로 상용화되었다. 이러한 메쉬 구조에서 지름(diameter)과 고장허용도(fault tolerance) 를 개선한 상호연결망이 토러스 구조인데, 토러스는 메쉬의 행과 열에 하나의 에지를 추가하여 각각의 행과 열이 링 형 태를 갖는 연결망이다. 이러한 토러스 구조는 $\mathrm{MPP}$ (Goodyear Aerospace), MP-I(MASPAR), Victor(IBM), Paragon(Intel), T3D(Cray) 등에 상용화되어 사용되고 있고 [3], 최근에도 연구되고 있다[13,14,15].

하이퍼큐브는 노드 및 에지 대칭이고 단순한 재귀적 구조 를 가지고 있어서 각종 응용 분야에서 요구하는 통신망 구 조를 쉽게 제공할 수 있는 장점이 있으며, Intel iPSC, nCUBE, Connection Machine CM-2, SGI Origin 2000 등의 시스템에서 사용되고 있다[7]. $\mathrm{HCN}$ 과 $\mathrm{HFN}$ 은 하이퍼큐브의 장점을 가지면서 망비용을 개선한 연결망으로 하이퍼큐브를 
기본 모듈로 사용하여 모듈 내부의 노드와 모듈 외부의 노 드를 연결하여 구성되어 있다. $\mathrm{HCN}$ 과 $\mathrm{HFN}$ 의 여러 가지 성 질은 $[2,6,8,9,10,12,18]$ 에서 분석되었다. 특히, $[12,18]$ 에서 $2 n-$ 차원 하이퍼큐브와 $\operatorname{HCN}(n, n)$ 과 $\operatorname{HFN}(n, n)$ 사이의 임 베딩 이 분석되었는데, $2 n$-차원 하이퍼큐브가 $\operatorname{HCN}(n, n)$ 과 $\operatorname{HFN}(n, n)$ 에 연장율 3 , 평균연장율 2 이하로 임베딩 가능함 을 보였고, $H C N(n, n)$ 과 $H F N(n, n)$ 이 $2 n$-차원 하이퍼큐브에 임베딩하는 비용이 $O(n)$ 임을 보였다.

다양한 연결망 구조에서 여러 가지 문제들을 풀기 위한 많은 병렬 알고리즘이 설계되고 있는데 이러한 알고리즘을 원래와는 다른 연결망 구조에서 실행시킬 수 있는지를 분석 하는 임베딩은 병렬처리에서 중요한 의미를 갖는다 [1,2,8,12,16,18]. 임베딩은 한 연결망의 프로세서와 통신링크 를 다른 연결망의 프로세서와 통신링크들로 사상하는 방법 을 일컫는다. 임베딩의 비용을 측정하는 척도로는 연장율 (dilation), 밀집율(congestion), 확장율(expansion) 등이 있다.

본 논문에서는 $2^{2 n-k} \times 2^{k}$ 토러스와 $\operatorname{HCN}(n, n)$ 과 $\operatorname{HFN}(n, n)$ 사이의 임베딩을 분석한다. $2^{2 n-k} \times 2^{k}$ 토러스를 $H C N(n, n)$ 에 연장율 3 , 평균연장율 2 에 임베딩 가능함을 보이고, $2^{2 n-k} \times 2^{k}$ 토러스를 $\operatorname{HFN}(n, n)$ 에 연장율 3 과 밀집율 4, 평균연장율 2 로 임베딩 가능함을 보인다. 그리고 $\operatorname{HCN}(n, n)$ 과 $\operatorname{HFN}(n, n)$ 을 $2^{2 n-k} \times 2^{k}$ 토러스에 임베딩하는 비용이 $O(n)$ 임을 증명한다. $2 n$-차원 하이퍼큐브와 $2^{2 n-k} \times 2^{k}$ 토러스가 서로 다른 연결망 임에도 불구하고, 두 연결망과 $\operatorname{HCN}(n, n), \operatorname{HFN}(n, n)$ 과의 임 베딩이 유사한 결과값을 갖는다는 것은 매우 흥미로운 결과 이다. 논문의 구성은 다음과 같다. 2 장에서는 본 논문에서 분석하고자하는 임베딩과 상호연결망에 대한 관련연구를 알 아보고, 3장에서는 상호연결망 사이의 임베딩을 분석하고, 마지막으로 결론을 맺는다.

\section{2. 관련연구}

그래프의 임베딩(embedding)은 어떤 그래프가 다른 그래 프 구조에 포함 혹은 어떻게 연관되어 있는지를 알아보기 위해 특정한 그래프를 다른 그래프에 사상(mapping)하는 것 이다. 그래프 $G$ 의 그래프 $H$ 에 대한 임베딩 $f$ 는 다음과 같이 정의되는 함수의 쌍 $(\varnothing, \rho)$ 을 말한다. 임베딩 함수에서 $\varnothing$ 는 $G$ 의 정점 집합 $V(v)$ 를 $H$ 의 정점 집합 $V(H)$ 에 대응시키는
함수이고, $\rho$ 는 $G$ 의 에지 $e=(v, w)$ 에서 $\varnothing(v)$ 와 $\varnothing(w)$ 를 잇는 $H$ 상의 경로로 대응시키는 함수이다. 임베딩의 비용을 나타내 는 척도는 연장율, 밀집율, 확장율 등이 널리 사용되고 있다. 연장율은 그래프 $G$ 의 에지 $e$ 를 그래프 $H$ 상의 에지로 사상 할 때 경로 $\rho(e)$ 의 길이를 말하고, 임베딩 $f$ 의 연장율은 $G$ 의 모든 에지의 연장율 중 최대값이다. 밀집율은 그래프 $H$ 의 어떤 에지 $e^{\prime}$ 를 지나는 경로 $\rho(e)$ 의 개수를 말하고, 임베딩 $f$ 의 밀집율은 그래프 $H$ 의 모든 에지의 밀집율 중 최대값이 다. 임베딩 $f$ 의 확장율은 $G$ 의 정점의 개수에 대한 $H$ 의 정점 의 개수의 비를 말한다. 이러한 임베딩의 비용에서 연장율 은 어떤 연결망을 다른 연결망에서 시뮬레이션 할 때 요구 되는 통신비용을 나타내고, 밀집율은 시뮬레이션 할 때 연 결망 $H$ 의 한 에지에 걸리는 부하를 나타낸다. 그리고 확장 율은 그래프 $G$ 를 시뮬레이션 하기 위해 필요한 그래프 $H$ 의 최소 프로세서의 수를 나타내며 하드웨어 비용과 관련된다.

상호연결망 $\operatorname{HCN}(n, n)$ 은 $n$-차원 하이퍼큐브를 기본 모듈 로 사용한다. $\operatorname{HCN}(n, n)$ 은 $2^{2 n}$ 개의 노드들을 포함하고 $(n+1) 2^{2 n-1}$ 개 에지를 포함하며, 분지수는 $n+1$ 이다. $\operatorname{HCN}(n, n)$ 은 $2^{n}$ 개의 기본 모듈로 구성되어 있고, 각 노드는 $(I, J)$ 과 같 이 두 개의 주소로 구성이 되며, 각 노드는 각각에 연결된 $n+1$ 개의 에지를 갖는데, $n$ 개의 에지는 기본 모듈 내부의 노 드를 연결하는 에지로 내부에지라고 하고, 서로 다른 기본 모듈 내부에 있는 노드를 연결하는 에지를 외부에지라고 하 며, 하나만 존재한다. 노드 주소 $(I, J)$ 에서 $I$ 는 기본모듈을 인식하는 주소이고, $J$ 는 기본모듈 내부의 노드를 인식하는 주소이다. 외부에지는 지름에지(diameter link)와 비지름에지 (non-diameter link)로 구분한다. 지름에지는 노드의 주소가 $0 \leq I \leq\left(2^{n}-1\right)$ 와 $0 \leq J \leq\left(2^{n}-1\right)$ 를 만족하는 노드 $(I, I)$ 와 노드 $(J, J)$ 를 연결하는 외부에지를 말하고, 이때 주소 $I$ 와 $J$ 는 보 수 관계이다. 지름에지가 아닌 외부에지를 비지름에지라 하 고, $(I, J)$ 와 $(J, I)$ 를 연결하는 에지이다 $(I \neq J)$. 그림 1 은 $\operatorname{HCN}(3,3)$ 의 구조를 보여준다.

상호연결망 $\operatorname{HFN}(n, n)$ 의 구조는 $n$-차원 folded-하이퍼큐 브를 기본 모듈로 사용한다. folded-하이퍼큐브는 하이퍼큐 브의 각 노드에서 주소가 서로 보수관계인 노드들간에 에지 가 한 개씩 추가된 구조이다. 따라서 folded-하이퍼큐브는 하이퍼큐브보다 분지수가 1 증가한 $n+1$ 이고, 지름은 하이퍼 큐브의 절반을 갖는다. 상호연결망 $\operatorname{HFN}(n, n)$ 의 구조는

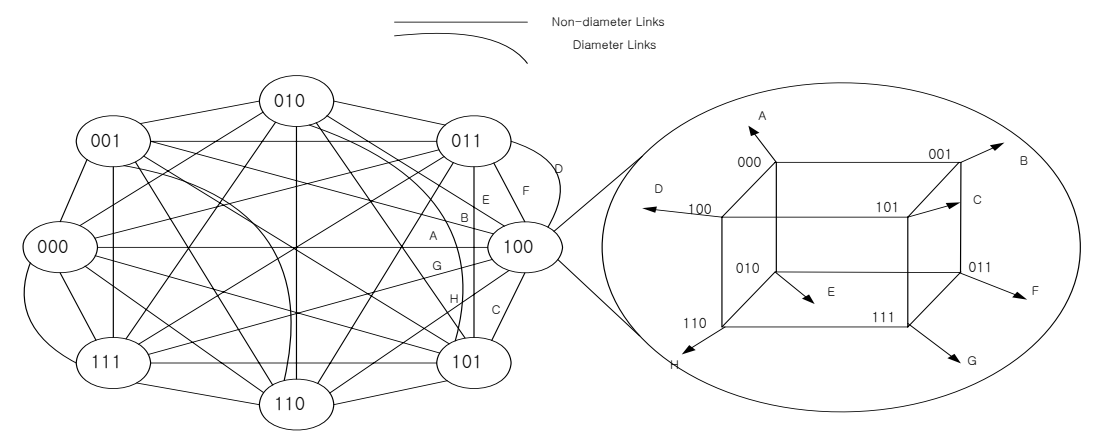

(그림 1) $\operatorname{HCN}(3,3)$ 


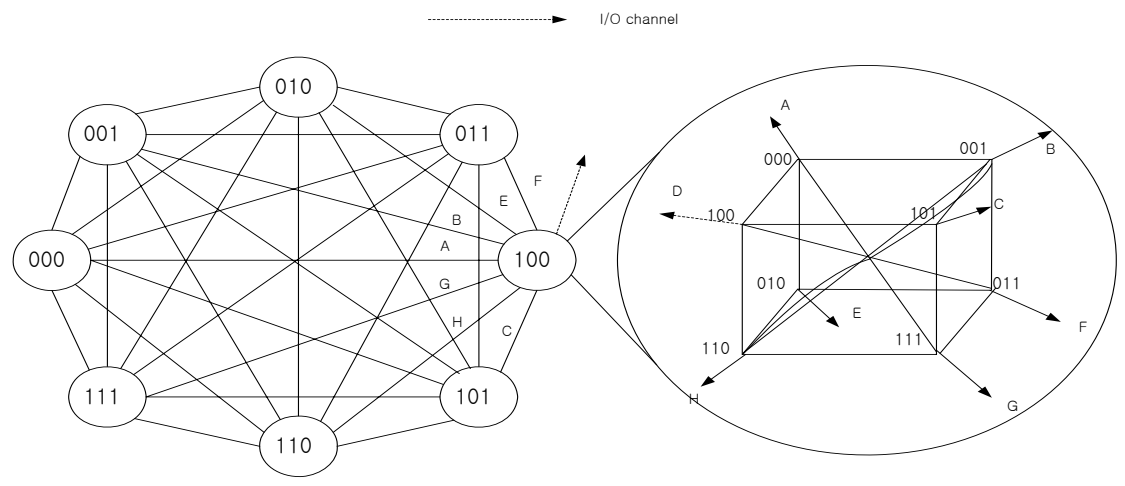

(그림 2) HFN(3,3)

$\operatorname{HCN}(n, n)$ 의 구조에서 다음 두 가지의 변형을 적용한 구조 이다. 첫째, 하이퍼큐브 대신에 folded-hypercube를 기본 모 듈로 사용한다. 둘째, $\operatorname{HCN}(n, n)$ 구조에서 지름 에지를 제거 한다.

위의 조건을 갖는 $H F N(n, n)$ 은 $2^{2 n}$ 개의 노드들을 가지고 $(n+2) 2^{2 n-1}-2^{n-1}$ 개의 에지들을 가진다. $H F N(n, n)$ 의 각 노드는 분 지수 $n+2$ 를 가진다. (그림 2)는 $H F N(3,3)$ 의 구조를 보여준다.

$m$-차원 메쉬 $M_{m}(N)$ 은 $N^{m}$ 개의 노드와 $m N^{m}-m N^{m-1}$ 개의 에지로 구성된다. 각 노드는 $m$-차원 벡터로 표현 될 수 있 고, 임의의 두 노드의 주소가 한 개의 차원에서 1 차이 날 때 그들 사이에 에지가 있다. $M_{m}(2)$ 는 하이퍼큐브이며, $M_{2}(N)$ 은 격자 형태의 2-차원 배열이다. 특히 수직 방향으 로 $n$ 개씩, 수평 방향으로 $k$ 개씩의 노드로 구성된 2-차원 메 쉬를 $M_{n, k}$ 로 나타낸다. 2-차원 메쉬는 정규 그래프가 아니고 노드 대칭적이지 않으며, $n \times k$ 개의 노드로 구성된 2-차원 메 쉬 $M_{n, k}$ 의 지름은 $n+k-2$ 이다. 낮은 차원의 메쉬는 설계하기 쉽고 알고리즘 관점에서도 매우 유용하므로 병렬처리 컴퓨 터의 연결망으로 많이 쓰이고 있으며, 높은 차원의 메쉬 일 수록 지름이 작아지고 여러 가지 병렬 알고리즘을 빨리 수 행할 수 있지만, 비용이 많이 드는 단점이 있다. 이러한 메 쉬의 지름을 개선한 연결망으로 토러스(torus)가 있다. 토러 스는 메쉬의 행과 열을 링 형태를 갖도록 하는 랩어라운드 (wraparound) 에지라고 불리는 에지를 추가하여 구성한 연 결망이다. $k \times n$ 으로 표현되는 토러스는 $k \times n$ 개의 노드와 $2 k n$ 개 의 에지로 구성되며, 분지수는 4 , 지름은 $\left\lfloor\frac{k}{2}\right\rfloor+\left\lfloor\frac{n}{2}\right\rfloor$ 이다[16].

\section{3. 임베딩}

본 논문에서는 $2^{2 n-k} \times 2^{k}$ 토러스 구조에서 노드 $T$ 의 주소 를 $T=t_{1} t_{2} \cdots t_{n} t_{n+1} t_{n+2} \cdots t_{2 n}$ 와 같은 연속된 $2 n$ 개의 비트스트링으 로 표현하고, 1 부터 $n$ 번째 까지 비트스트링이 같은 노드들 을 하나의 그룹으로 설정하겠다. 예를 들어, $n=2$ 이고 $k=2$ 인 $2^{2} \times 2^{2}$ 토러스에서는 한 노드의 주소 길이가 4-비트이고, 4 개 비트에서 가장 왼쪽에서 2 번째까지의 비트스트링이 00 , $01,11,10$ 으로 구성된 4 개의 주소를 그룹으로 나눌 수가 있 다. (그림 3)은 $2^{2} \times 2^{2}$ 토러스의 각 노드 주소를 그레이코드 (Gray Code)[6]로 표현 하였고, 처음 2비트가 같은 노드들을 하나의 그룹으로 분류하였다. 여기서 나타내는 그레이코드

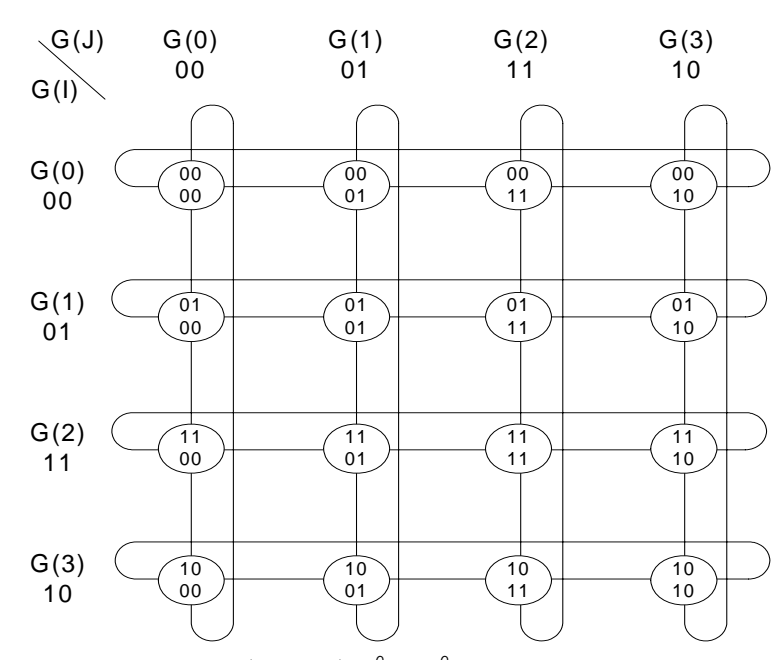

(그림 3) $2^{2} \times 2^{2}$ 토러스

는 Binary Reflected Gray Code를 의미한다. 그레이코드는 연속된 2진수 사이에 오직 한 개의 비트만 변화하는 코딩 방식의 하나로 자기 보수성과 주기성을 갖는다. $(n+1)$-비트 그레이코드 $g_{n} g_{n-1} g_{n-2 .} . g_{1} g_{0}$ 는 임의의 $(n+1)$-비트 이진수 $b_{n} b_{n-1} b_{n-2 \ldots} b_{1} b_{0}$ 으로부터 다음과 같이 유도될 수 있다.

$$
g_{i}=b_{i} \oplus b_{i+1}, 0 \leq i \leq n-1, g_{n}=b_{n} .
$$

또 정수 $i\left(0 \leq i \leq 2^{n-1}\right)$ 를 2 진 비트스트링으로 표현한 것을 $B_{i}$ 라 하면, $B^{\prime}$ 는 $B_{i}$ 를 오른쪽으로 한 비트씩 이동(shift)하여 얻어진 것으로 첫 번째 비트에는 0 이 삽입되는 2 진 비트스 트링이라 할 때, $i$-비트 그레이코드 $G_{i}$ 는 다음과 같이 정의 된다.

$$
G_{i}=B_{i} \oplus B^{\prime}{ }_{i}
$$

위의 수식에서 사용한 심벌 $\oplus$ 는 Exclusive-OR 연산이다. 예를 들어, $B_{i}$ 가 011010 이면, $B^{\prime}{ }^{\prime}$ 는 001101 이고, 그레이코드 는 010111이다.

정리 1. $2^{2 n-k} \times 2^{k}$ 토러스는 $\operatorname{HFN}(n, n)$ 에 연장율 3 과 밀집 율 4 로 임베딩 가능하다 $(k \leq n)$.

증명. $n$-비트 그레이코드의 구성은 $G(i)$ 가 $0 \leq i \leq 2 n-1$ 일 때 $G(0), G(1), G(2), \ldots, G(2 n-1)$ 와 같이 표현할 수 있다[6]. 
이와 같은 표현법을 이용하여 $2^{2 n-k} \times 2^{k}$ 토러스 $T\left(t_{1} t_{2} \ldots t_{n} t_{n+1} t_{n+2} \ldots t_{2 n}\right)$ 의 비트스트링에서 1 부터 $n$ 번째까지의 비트스트링 $t_{1} t_{2} . t_{n}$ 을 $G(I)$ 라 하고, $n+1$ 부터 $2 n$ 까지의 비트스 트링 $t_{n+1} t_{n+2} \ldots t_{2 n}$ 을 $G(J)$ 로 각각 구분하여 표기하면, $G(I)$ 는 하나의 그룹을 나타내고 $G(J)$ 는 그룹 내부의 노드 주소를 나타낸다. 따라서 $2^{2 n-k} \times 2^{k}$ 토러스의 임의의 노드 $T\left(t_{1} t 2 \ldots t_{n} t_{n+1} t_{n+2} \ldots t_{2 n}\right)$ 는 $T(G(I) G(J))$ 와 같이 표현할 수 있다 $(0 \leq I \leq 2 n-1,0 \leq J \leq 2 n-1)$. 예를 들면, 그림 4 에서 노드 0111 은 $T(G(1) G(2))$ 이다. 그리고 $H F N(n, n)$ 의 임의의 노드 $S$ 는 $S(G(I), G(J))$ 라 표현하겠다[7].

$2^{2 n-k} \times 2^{k}$ 토러스를 $\operatorname{HFN}(n, n)$ 에 임 베딩 했을 때, 토러스의 인접한 노드의 경우를 아래와 같이 나누어서 각각의 연장율 을 분석하겠다.

경우 1. $(T(G(I) G(J)), T(G(I) G(J+1)))$ 일 때 : $2^{2 n-k} \times 2^{k}$ 토 러스에서 노드 $T(G(I) G(J))$ 과 $T(G(I) G(J+1)$ 의 주소 중 $G(I)$ 는 동일하므로 같은 그룹에 존재하고, 그룹 내부의 주소를 나타내는 $G(J)$ 과 $G(J+1)$ 는 1 -비트 다른 그레이코드로 연결 되어 있는 노드임을 알 수 있다. 따라서 $H F N$ 의 정의에 의 해 $\operatorname{HFN}(n, n)$ 의 동일한 모듈 내부에 있는 노드임을 알 수 있고, 서로 인접한 노드이므로 연장율 1 에 임베딩 가능함을 알 수 있다.

경우 2. $(T(G(I) G(J)), T(G(I+1) G(J)))$ 일 때 : $2^{2 n-k} \times 2^{k}$ 토 러스에서 두 노드는 서로 다른 그룹 내에 존재하는 노드들 로 $\operatorname{HFN}(n, n)$ 에 임베딩 했을 때 지나가는 노드의 경로는 $S(G(I), G(J)) \quad \rightarrow \quad S(G(J), G(I)) \quad \rightarrow \quad S(G(J), G(I+1)) \quad \rightarrow$ $S(G(I+1), G(J))$ 와 같은 경로로 연결되므로 연장율 3 에 임베 딩 가능함을 알 수 있다.

경우 2.1 경우 2 에서 $G(I)=G(J)$ 일 때 : 두 노드는 $S(G(I), G(J)) \quad \rightarrow \quad S(G(I), G(J+1)) \quad \rightarrow \quad S(G(J+1), G(I))$ $(=S(G(I+1), G(I)))$ 와 같은 경로로 연결 되거나 $S(G(I), G(J))$ $\rightarrow S(G(J), G(I)) \rightarrow S(G(J), G(I+1))(=S(G(I+1), G(J)))$ 와 같은 경로로 연결되므로 연장율 2 에 임베딩 가능함을 알 수 있다.

이상의 경우에서 증명한 바와 같이 $2^{2 n-k} \times 2^{k}$ 토러스를 $\operatorname{HFN}(n, n)$ 에 임베딩하는 연장율은 3 이하이다.

$2^{2 n-k} \times 2^{k}$ 토러스를 $\operatorname{HFN}(n, n)$ 으로 임베딩했을 때, 상호연 결망 $\operatorname{HFN}(n, n)$ 의 에지 $e$ 를 아래와 같은 경우로 나누어서 각 에지 $e$ 가 사용된 빈도수에 의해 밀집율을 분석하겠다.

경우 1. 에지e 에 연결된 두 노드가 같은 모듈 안에 있으 며 서로 보수 일 때, 위의 연장율의 증명에서 연결되는 경 로를 보면 보수인 두 노드를 연결하는 에지는 존재하지 않 는다. 그러므로 에지 $e$ 는 밀집율이 0이다.

경우 2. 에지 $e$ 가 $(S(G(I), G(J)), S(G(I), G(J+1)))$ 일 때, 에 지 $e$ 는 같은 모듈 안에 있으며 각각 1 비트 다른 노드들을 연결하는 내부 에지 이다. 토러스의 하나의 그룹이 $\operatorname{HFN}(n, n)$ 내의 하나의 모듈로 임베딩 되기 때문에 내부 에 지의 밀집율이 1 임을 알 수 있다.

경우 3. 에지 $e$ 가 $(S(G(I), G(J)), S(G(J), G(I)))$ 일 때, 에지 $e$ 는 서로 다른 모듈에 속해 있는 두 노드를 연결하는 외부 에지이다. 토러스에서 다음과 같이 노드를 설정하여 에지 $e$ 가 몇 번 사용되었는지를 분석하겠다.
1) $(T(G(I-1), G(J)), T(G(I), G(J)))$

2) $(T(G(I+1), G(J)), T(G(I), G(J)))$

3) $(T(G(J-1), G(I)), T(G(J), G(I)))$

4) $(T(G(J+1), G(I)), T(G(J), G(I)))$

이와 같은 노드를 $\operatorname{HFN}(n, n)$ 에 사상하면 $e$ 를 포함하는 경로는 다음과 같다.

1) $S(G(I-1), G(J)) \rightarrow S(G(J), G(I-1)) \rightarrow S(G(J), G(I))$ $\stackrel{e}{\longrightarrow} S(G(I), G(J))$

2) $S(G(I+1), G(J)) \rightarrow S(G(J), G(I+1)) \rightarrow S(G(J), G(I))$ $\stackrel{e}{\longrightarrow} S(G(I), G(J))$

3) $S(G(J-1), G(I)) \rightarrow S(G(I), G(J-1)) \rightarrow S(G(I), G(J))$ $\stackrel{e}{\longrightarrow} S(G(J), G(I))$

4) $S(G(J+1), G(I)) \rightarrow S(G(I), G(J+1)) \rightarrow S(G(I), G(J))$ $\stackrel{e}{\longrightarrow} S(G(J), G(I))$

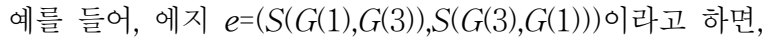

1) $(T(G(0), G(3)), T(G(1), G(3)))$

2) $(T(G(2), G(3)), T(G(1), G(3)))$

3) $(T(G(2), G(1)), T(G(3), G(1)))$

4) $(T(G(4), G(1)), T(G(3), G(1)))$

이와 같이 노드들을 설정할 수 있다. 설정된 노드들을 $\operatorname{HFN}(n, n)$ 에 사상하면 $e$ 를 포함하는 경로는 다음과 같다.

1) $S(G(0), G(3)) \quad \rightarrow \quad S(G(3), G(0)) \quad \rightarrow \quad S(G(3), G(1))$

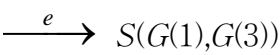

2) $S(G(2), G(3)) \quad \rightarrow \quad S(G(2), G(2)) \quad \rightarrow \quad S(G(3), G(1))$

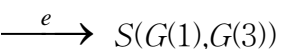

3) $S(G(2), G(1)) \quad \rightarrow \quad S(G(1), G(2)) \quad \rightarrow \quad S(G(1), G(3))$ $\stackrel{e}{\longrightarrow} S(G(3), G(1))$

4) $S(G(4), G(1)) \quad \rightarrow \quad S(G(1), G(4)) \quad \rightarrow \quad S(G(1), G(3))$ $\stackrel{e}{\longrightarrow} S(G(3), G(1))$

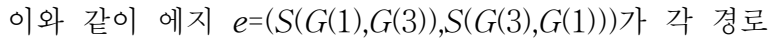
를 통하여 각각 한번씩 사용되었다는 것을 알 수 있으므로 에지 $e$ 의 사용 빈도가 4 번이라는 것을 알 수 있다. 이러한 결과로 밀집율은 4 임을 알 수 있다.

따름정리 $12^{2 n-k} \times 2^{k}$ 토러스의 $\operatorname{HFN}(n, n)$ 에 대한 임베딩 의 평균 연장율은 2 이하이다 $(k \leq n)$.

증명 $2^{2 n-k} \times 2^{k}$ 토러스를 $\operatorname{HFN}(n, n)$ 에 임베딩 했을 때, 임 베딩의 평균 연장율은 $2^{2 n-k} \times 2^{k}$ 토러스의 모든 에지의 연장 율을 합하여 전체 에지 개수로 나눈 값이다. $2^{2 n-k} \times 2^{k}$ 토러스 의 노드는 $\operatorname{HFN}(n, n)$ 의 노드와 일-대-일 사상되고, 토러스 의 에지 중 연장율 3 을 갖는 에지는 $\left(2^{n}-1\right) \times 2^{n}$ 개이고, 연장 율 2 를 갖는 에지는 $2^{n}$ 개이며 나머지 에지 $2^{n} \times 2^{n}$ 는 연장율 1 을 갖는다는 것을 정리 1 에 의해 알 수 있다. 토러스의 전 
체 에지의 개수는 $2 \times 2^{2 n}$ 이다. 따라서 평균 연장율은 $\left(1\left(2^{n} \times 2^{n}\right)+2\left(2^{n}\right)+3\left(2^{n}-1\right) \times 2^{n}\right) / 2 \times 2^{2 n}$ 즉, $2-1 /\left(2 \times 2^{2 n}\right)$ 이므로 대 략 2 보다 적은 값을 갖는다.

정리 2. 상호연결망 $\operatorname{HFN}(n, n)$ 을 $2^{2 n-k} \times 2^{k}$ 토러스에 임베 딩하는 연장율은 $O(n)$ 이다.

증명. 상호연결망 $\operatorname{HFN}(n, n)$ 의 임의의 노드 $S$ 는 $S(G(I), G(J))$ 로 표현 하고, $2^{2 n-k} \times 2^{k}$ 토러스의 노드 $T$ 는 $T(G(I) G(J))$ 로 표현 하겠다 $(0 \leq I, J \leq 2 n-1) . H F N(n, n)$ 의 두 노드 $S(G(I), G(J))$ 와 $S(G(J), G(I))$ 를 토러스로 사상했을 때 사상된 토러스에서의 두 노드사이의 최대 거리를 통하여 연 장율을 살펴보겠다.

$2^{2 n-k} \times 2^{k}$ 토러스의 인접한 두 노드는 $1-$ 비트 다른 노드로 연결이 되어있으며, 두 노드의 거리가 최대가 될 경우는 $2^{2 n-k} \times 2^{k}$ 토러스의 정의에 따라 두 노드의 행과 열의 거리가 각각 $\left\lfloor\frac{2 n-k}{2}\right\rfloor,\left\lfloor\frac{k}{2}\right\rfloor$ 가 될 때 이다. 다시 말해서 $G(0)$ 부터 $G(2 n-1)$ 까지의 비트스트링으로 구성된 $2^{2 n-k} \times 2^{k}$ 토러스에서 $I, J, I^{\prime}, J^{\prime}$ 가 0 부터 $2 n-1$ 까지인 임의의 두 노드를 $T(G(I) G(J))$ 와 $T\left(G\left(I^{\prime}\right) G\left(J^{\prime}\right)\right)$ 라 했을 때, 두 노드의 행과 열에서 $\left|T(G(I))-T\left(G\left(I^{\prime}\right)\right)\right|$ 와 $\left|T(G(J))-T\left(G\left(J^{\prime}\right)\right)\right|$ 의 값이 각각 $2 n-1$ 일 때 최대 거리를 갖는다 $\left(I \neq I^{\prime}, J \neq J^{\prime}\right) . \operatorname{HFN}(n, n)$ 의 인접해 있는 두 노드 $S(G(0), G(2 n-1))$ 와 $S(G(2 n-1), G(0))$ 를 토러스 의 두 노드 $T(G(0) G(2 n-1))$ 와 $T(G(2 n-1) G(0))$ 에 사상하면, 사상된 두 노드 사이의 거리인 $\left|T(G(I))-T\left(G\left(I^{\prime}\right)\right)\right|$ 와 $\left|T(G(J))-T\left(G\left(J^{\prime}\right)\right)\right|$ 의 값이 각각 $2 n-1$ 임을 알 수 있으며, 이 때의 두 노드의 거리는 $2 n$ 임을 알 수 있다. 따라서 $\operatorname{HFN}(n, n)$ 을 $2^{2 n-k} \times 2^{k}$ 토러스에 임베딩하기 위해 필요한 연 장율은 $2 n$ 이므로 $O(n)$ 이 됨을 알 수 있다.

$2^{2 n-k} \times 2^{k}$ 토러스를 $\operatorname{HCN}(n, n)$ 에 임베딩하는 방법을 알아본 다. $2^{2 n-k} \times 2^{k}$ 토러스에서 한개 그룹은 $\operatorname{HCN}(n, n)$ 에서 한개 모 듈로 대응(그룹 내부의 노드는 모듈 내부의 노드에 $1: 1$ 사 상)되고, 그룹과 그룹을 연결하는 에지의 두 노드가 사상된 $\operatorname{HCN}(n, n)$ 의 두 노드를 연결하는 에지의 수로 연장율을 분 석한다.

정리 3. $2^{2 n-k} \times 2^{k}$ 토러스는 $\operatorname{HCN}(n, n)$ 에 연장율 3 에 임 베 딩 가능하다 $(k \leq n)$.

증명. $n$-비트 그레이코드의 구성은 $G(i)$ 가 $0 \leq i \leq 2 n-1$ 일 때, $G(0), G(1), G(2), \ldots, G(2 n-1)$ 와 같이 표현할 수 있다[7]. 이와 같은 표현법을 이용하여 $2^{2 n-k} \times 2^{k}$ 토러스 $T\left(t_{1} t_{2} \ldots t_{n} t_{n+1} t_{n+2} \ldots t_{2 n}\right)$ 의 비트스트링에서 1 부터 $n$ 번째까지의 비트스트링 $t_{1} t_{2} . t_{n}$ 을 $G(I)$ 라 하고, $n+1$ 부터 $2 n$ 까지의 비트스 트링 $t_{n+1} t_{n+2 \ldots} \ldots t_{2 n}$ 을 $G(J)$ 로 각각 구분하여 표기하면, $G(I)$ 는 하나의 그룹을 나타내고 $G(J)$ 는 그룹 내부의 노드 주소를 나타낸다. 따라서 $2^{2 n-k} \times 2^{k}$ 토러스의 임의의 노드 $T\left(t_{1} t 2 \ldots t_{n} t_{n+1} t_{n+2} \ldots t_{2 n}\right)$ 는 $T(G(I) G(J))$ 와 같이 표현할 수 있다 $(0 \leq I \leq 2 n-1,0 \leq J \leq 2 n-1)$. 예를 들면, 그림 4 에서 노드 0111 은 $T(G(1) G(2))$ 이다. 그리고 $H C N(n, n)$ 의 임의의 노드 $S$ 는 $S(G(I), G(J))$ 라 표현하겠다. 토러스를 $H C N(n, n)$ 에 임베딩 했을 때의 경우를 아래와 같이 나누어서 각각의 연장율을 분석하겠다.
경우 1. $(T(G(I) G(J)), T(G(I) G(J+1)))$ 일 때 : $2^{2 n-k} \times 2^{k}$ 토러 스에서 두 노드는 같은 그룹 안에서 에지가 존재하는 경우 이며 또한 1 비트 다른 그레이코드로 연결되어 있는 노드들 임을 알 수 있다. 따라서 $H C N$ 의 정의에 의해 $H C N(n, n)$ 의 동일한 모듈 내부에 있는 노드임을 알 수 있고, 서로 인접 한 노드이므로 연장율 1 에 임베딩 가능함을 알 수 있다.

경우 2. $(T(G(I) G(J)), T(G(I+1) G(J)))$ 일 때 : $2^{2 n-k} \times 2^{k}$ 토 러스에서 두 노드는 서로 다른 그룹 안에 존재하는 노드들 로 $\operatorname{HCN}(n, n)$ 에 임베딩 했을 때 지나가는 노드의 경로는 $S(G(I), G(J)) \rightarrow S(G(J), G(I)) \rightarrow S(G(J), G(I+1)) \quad \rightarrow$ $S(G(I+1), G(J))$ 와 같은 경로로 연결 되므로 연장율 3 에 임 베딩 가능함을 알 수 있다.

경우 2.1. 경우 2 에서 $G(I)=G(J)$ 일 때 : 두 노드는 $S(G(I), G(J)) \quad \rightarrow \quad S(G(I), G(J+1)) \quad \rightarrow \quad S(G(J+1), G(I))$ $(=S(G(I+1), G(I)))$ 와 같은 경로로 연결 되거나 $S(G(I), G(J))$ $\rightarrow S(G(J), G(I)) \rightarrow S(G(J), G(I+1))(=S(G(I+1), G(J)))$ 와 같은 경로로 연결이 되므로 연장율 2에 임베딩 가능함을 알 수 있다.

이상의 2가지 경우에서 증명한 바와 같이 토러스를 $\operatorname{HCN}(n, n)$ 에 임베딩을 하기 위해 필요한 연장율은 3 이하이다.

따름정리 $22^{2 n-k} \times 2^{k}$ 토러스의 $H C N(n, n)$ 에 대한 임베딩의 평균 연장율은 2 이하이다 $(k \leq n)$.

증명 $2^{2 n-k} \times 2^{k}$ 토러스를 $\operatorname{HCN}(n, n)$ 에 임베딩 했을 때, 임 베딩의 평균 연장율은 토러스의 모든 에지의 연장율을 합하 여 전체 에지 개수로 나눈 값이다. 토러스의 노드는 $\operatorname{HCN}(n, n)$ 의 노드와 일-대-일 사상되고, 토러스의 에지 중 연장율 3 을 갖는 에지는 $\left(2^{n}-1\right) \times 2^{n}$ 개이고, 연장율 2 를 갖는 에지는 $2^{n}$ 개이며 나머지 에지 $2^{n} \times 2^{n}$ 는 연장율 1 을 갖는다는 것을 정리 2에 의해 알 수 있다. 토러스의 전체 에지의 개 수는 $2 \times 2^{2 n}$ 이다. 따라서 평균 연장율은 $\left(1\left(2^{n} \times 2^{n}\right)+2\right.$ $\left.\left(2^{n}\right)+3\left(2^{n}-1\right) \times 2^{n}\right) / 2 \times 2^{2 n}$ 즉, $2-1 /\left(2 \times 2^{2 n}\right)$ 이므로 대략 2 보다 적은 값을 갖는다.

정리 4. 상호연결망 $\operatorname{HCN}(n, n)$ 을 $2^{2 n-k} \times 2^{k}$ 토러스에 임베 딩하는 연장율은 $O(n)$ 이다.

증명. 상호연결망 $\operatorname{HCN}(n, n)$ 의 임의의 노드 $S$ 는 $S(G(I), G(J))$ 로 표현 하고, $2^{2 n-k} \times 2^{k}$ 토러스의 노드 $T$ 는 $T(G(I) G(J))$ 로 표현 하겠다 $(0 \leq I, J \leq 2 n-1) . H C N(n, n)$ 의 두 노드 $S(G(I), G(J))$ 와 $S(G(J), G(I))$ 를 토러스로 사상했을 때 사상된 토러스에서의 두 노드사이의 최대 거리를 통하여 연 장율을 살펴보겠다.

$2^{2 n-k} \times 2^{k}$ 토러스의 인접한 두 노드는 1 -비트 다른 노드로 연결이 되어있으며, 두 노드의 거리가 최대가 될 경우는 $2^{2 n-k} \times 2^{k}$ 토러스의 정의에 따라 두 노드의 행과 열의 거리가 각각 $\left\lfloor\frac{2 n-k}{2}\right\rfloor,\left\lfloor\frac{k}{2}\right\rfloor$ 가 될 때 이다. 다시 말해서 $G(0)$ 부터 $G(2 n-1)$ 까지의 비트스트링으로 구성된 $2^{2 n-k} \times 2^{k}$ 토러스에서 $I, J, I^{\prime}, J^{\prime}$ 가 0 부터 $2 n-1$ 까지인 임의의 두 노드를 $T(G(I) G(J))$ 와 $T\left(G\left(I^{\prime}\right) G\left(J^{\prime}\right)\right)$ 라 했을 때, 두 노드의 행과 열에서 
$\left|T(G(I))-T\left(G\left(I^{\prime}\right)\right)\right|$ 와 $\left|T(G(J))-T\left(G\left(J^{\prime}\right)\right)\right|$ 의 값이 각각 $2 n-1$ 일 때 최대 거리를 갖는다 $\left(I \neq I^{\prime}, J \neq J^{\prime}\right) . H C N(n, n)$ 의 인접해 있는 두 노드 $S(G(0), G(2 n-1))$ 와 $S(G(2 n-1), G(0))$ 를 토러스 의 두 노드 $T(G(0) G(2 n-1))$ 와 $T(G(2 n-1) G(0))$ 에 사상하면, 사상된 두 노드 사이의 거리인 $\left|T(G(I))-T\left(G\left(I^{\prime}\right)\right)\right|$ 와 $\left|T(G(J))-T\left(G\left(J^{\prime}\right)\right)\right|$ 의 값이 각각 $2 n-1$ 임을 알 수 있으며, 이 때의 두 노드의 거리는 $2 n$ 임을 알 수 있다. 따라서 $\operatorname{HCN}(n, n)$ 을 $2^{2 n-k} \times 2^{k}$ 토러스에 임베딩하기 위해 필요한 연 장율은 $2 n$ 이므로 $O(n)$ 이 됨을 알 수 있다.

\section{4. 결 론}

본 논문에서는 상호 연결망으로 널리 사용되고 있는 $2^{2 n-k} \times 2^{k}$ 토러스를 $H C N(n, n)$ 에 연장율 3 에 임베딩 가능함을 보였고, 평균연장율이 2 이하임을 보였으며, $2^{2 n-k} \times 2^{k}$ 토러스 를 $\operatorname{HFN}(n, n)$ 에 연장율 3 과 밀집율 4 로 임베딩 가능함을 보 였고, 평균연장율이 2 이하임을 보였다. 그리고 $\operatorname{HCN}(n, n)$ 과 $\operatorname{HFN}(n, n)$ 을 $2^{2 n-k} \times 2^{k}$ 토러스에 임베딩하는 연장율이 $O(n)$ 임 을 증명하였다. 이러한 결과는 토러스에서 이미 개발된 여 러 가지 알고리즘을 $H C N(n, n)$ 과 $\operatorname{HFN}(n, n)$ 에서 효율적으로 이용할 수 있음을 의미한다.

또한, $2 n$-차원 하이퍼큐브와 $2^{2 n-k} \times 2^{k}$ 토러스가 서로 다른 연결망임에도 불구하고, 두 연결망과 $\operatorname{HCN}(n, n), \operatorname{HFN}(n, n)$ 과의 임베딩이 유사한 결과값을 갖기 때문에 향후 두 연결 망 사이의 관계를 분석하는데, 본 논문의 연구 결과가 유용 한 연구자료가 될 것이다.

\section{참 고 문 헌}

[1] S. B. Akers and B. Krishnamurthy, "A Group-Theoretic Model for Symmertric Interconnection Network," IEEE Trans. Comput., Vol. 38, No. 4, pp. 555-565, 1989.

[2] L. Bjorneborn and G.-H. Chen, "Fault-tolerant cycle embedding in hierarchical cubic networks," Networks, Vol. 43, No. 1, pp. 28-38, 2004.

[3] J. Bruck, R. Cypher and C.-R. Ho, "Wildcard Dimensions, Coding Theory and Fault-Tolerant Meshes and Hypercubes," IEEE Trans. on Computers, vol. 44, No. 1, pp. 150-155, 1995

[4] N. Corp, "NCUBE/ten : an Overview," November 1985.

[5] W. Dally and C. Seitz, "The torus routing chip," Distributed Computing, Vol. 1, pp. 187-196, 1986.

[6] D. R. Duh, G. H. Chen and J. F. Fang, "Algorithms and Properties of a New Two-Level Network with Folded Hypercubes as Basic Modules," IEEE Trans. Parallel Distributed syst., Vol. 6, No. 7, pp. 714-723, 1995.

[7] T-Y. Feng, "A Survey of Interconnection Networks,", IEEE computer, pp. 12-27, December 1981.

[8] J.-S. Fu and G.-H. Chen, "Cycle embedding in faulty hierarchical cubic networks," Proc. the 2002 ACM Symposium on Applied Computing, pp. 860-864, 2002.

[9] J.-S. Fu and G.-H. Chen, "Hamiltonicity of the hierarchical cubic network," Theory of Computing Systems, Vol. 35, pp. 59-79, 2002.
[10] J.-S. Fu, G.-H. Chen and D.-R. Duh "Node-disjoint paths and related problems on hierarchical cubic networks," Networks, Vol. 40, No. 3, pp. 142-154, 2002.

[11] K. Ghose and K. R. Desai "Hierarchical Cubic Networks," IEEE Trans. Parallel Distributed syst., Vol. 6, No. 4, pp. 427-436, 1995.

[12] J.-S. Kim, H.-O. Lee and Y.-N. Heo, "Embedding among $\operatorname{HCN}(n, n), H F N(n, n)$ and hypercube," Proc. 8th International Conference on Parallel and Distributed Systems (ICPADS '01), pp. 533-540, 2001.

[13] E. Oh, H. Choi and J.-S. Kim, "Double-Link Failure Recovery in WDM Optical Torus Networks," Proc. The 18th International Conference on Information Networking (ICOIN '04), Lecture Notes in Computer Science (LNCS), Vol. 3090, pp. 708-717, 2004.

[14] E. Oh, J.-S. Kim and H.-O. Lee, "Fault-tolerant routing in mesh-connected 2D tori," Proc. The International Conference on Computational Science (ICCS '03), Lecture Notes in Computer Science (LNCS), Vol. 2659, pp.527-536, 2003.

[15] R. Pranav and L. Jenkins, "Fast and efficient submesh determination in faulty tori," International Conference on High Performance Computing (HiPC '04), Lecture Notes in Computer Science (LNCS), Vol. 3296, pp.474-483, 2004.

[16] A. Y. Wu, "Embedding of Tree Networks into Hypercubes," J. Parallel and Distributed Compyting, Vol. 2, pp. 238-249, 1985.

[17] S-K. Yun and K-H. Park, "Comments on 'Hierarchical Cubic Networks'," IEEE Trans. Parallel Distributed syst., Vol. 9, No. 4, pp. 410-414, 1998.

[18] 김종석, 이형옥, 허영남, "하이퍼큐브와 $\operatorname{HCN}(\mathrm{n}, \mathrm{n}), \mathrm{HFN}(\mathrm{n}, \mathrm{n})$ 사이의 임베딩”, 한국정보처리학회 논문지 A, Vol. 9-A, No. 2, pp. 191-196, 2002.

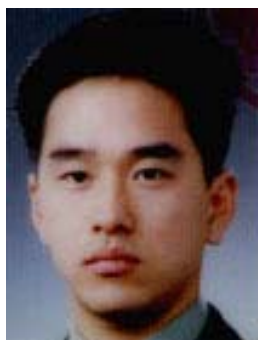

\section{김 종 석}

e-mail : rockhee7@gmail.com 1995년 2월 순천대학교 전자계산학과 (학사)

2001년 2월 순천대학교 컴퓨터과학과 (이학석사)

2004년 8월 순천대학교 컴퓨터과학과 (이학박사)

2007년 현재 오클라호마 주립대학교 컴퓨터과학과 박사후연구원

관심분야: 병렬 및 분산처리 알고리즘, 그래프이론, 상호연결망, 계산이론

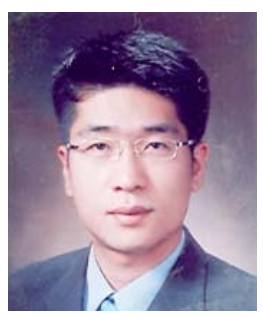

강 민 식

e-mail : kms@bogo.net

2002년 2월 순천대학교 컴퓨터과학과 (학사)

2004년 2월 순천대학교 컴퓨터과학과 (이학석사)

2007년 현재 (주)보고정보 기획영업팀 차장 관심분야 : 병렬 및 분산처리 알고리즘, 그래프이론, 상호연결망 